\title{
NICK RANSFORD: 'THERE IS A JOB TO DO SO LET'S GET ON WITH IT'
}

\author{
Nick Ransford is a consultant in special care dentistry at Birmingham \\ Community Healthcare NHS Trust. He has over 25 years' experience working \\ with adults with disabilities and medical conditions across the spectrum.
}

\section{Why did you choose to specialise in special care dentistry?}

I've been interested in all things medical right from my undergraduate days. I was also taken with the people side of the job - the behavioural elements and psychology. Those two have been long standing interests of mine and when special care dentistry was established as a specialty in this country, it seemed the obvious route for me to take.

\section{What part of your job do you find most challenging?}

I think it's juggling the competing demands on my time. As an NHS consultant, we have activity targets for number of patients and clinical sessions and at the same time we are tasked with leading service and organisational changes. There are a lot of these changes going on in Birmingham at the moment, as well as establishing managed clinical networks and all that entails. There is also quite a large teaching remit; teaching specialist trainees and establishing dentists with extended skills is quite a big training agenda. The other bit of the job, which often gets squeezed out, is the research element. For me that has been the part of my role that has kept stimulating my interest. It makes me ask questions about what we do clinically and how can we make it better. Unfortunately, that is the bit that loses out but it is the very thing that over the years has sustained my interest and enthusiasm for my work.
'Intranasal midazolam has revolutionised what we can do for our patients'

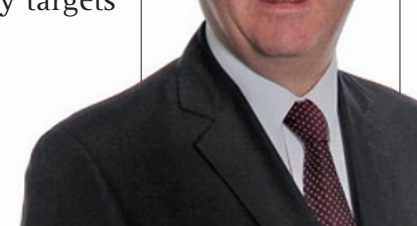

\section{What research are you doing at the moment?}

We are working on a project looking at whether IV sedation has any cardiac benefits in terms of doing invasive dental procedures on angina patients. We want to determine whether sedating these patients and relaxing them when taking teeth out actually reduces their markers of cardiac response. It is a very interesting project and clinically it's an important topic but actually getting the time to do it is a major challenge.

We have only just started this project. The hard work of getting ethical approval is complete. Now we are looking to recruit patients.

We are lucky because we have a new academic clinical fellow starting in Birmingham soon. We are hoping that that is going to provide the project with some much needed leadership. It's wonderful to get an enthusiastic person in because you need that to drive a project really.

\section{What inventions or} discoveries have made your job easier over the last 25 years?

Graham Manley, my colleague in the Royal Hospital for Neurodisability in Putney, introduced me to intranasal midazolam. It is used to get midazolam on board for people who cannot cooperate with having an IV cannula put in. In the past, trying to get some dentistry done for people with severe learning disabilities and challenging behaviours who won't tolerate an IV cannula has been very difficult. Commonly, they have ended up on a general anaesthetic (GA) list.

Of course trying to induce a GA
HAVE MORE QUESTIONS?

Nick Ransford will be speaking at this year's British Dental Conference \&t Exhibition 2014 which will be held from the 10-12 April 2014 in MCCC Manchester. Nick's talk is entitled 'Dental treatment in people with epilepsy' and will provide an update on the management of treatment in people prone to seizures and impart basic skills in seizure management. Book your place at the conference at www.bda.org/ conference. Extra and Expert BDA members all have free three-day VIP Conference Passes.

means getting a cannula in as well. So intranasal midazolam, which is a preparation invented at St Thomas' Hospital Pharmacy (and thank goodness that they did), enables you to administer a concentrated dose into the nose like a hayfever spray. Ten minutes later the vast majority of patients are sufficiently relaxed and calm to allow you to put an IV cannula in. It has absolutely revolutionised what we can do for them because now we are able to do most of the dental work under sedation in primary care in community health centres. It has cut the GA waiting lists quite significantly and I think it's improved no end what we can do for these patients. The feedback we get from carers and families is extremely appreciative. So that was an easy question to answer.

\section{You're speaking at this year's British Dental Conference \& Exhibition about treating people with epilepsy. What are the most important things to remember when managing the dental treatment of those prone to seizures?}

The main thing is not to be afraid of seizures. It doesn't happen very often in a dental practice but when it does it can look quite frightening for people who are not familiar with it. Seizures themselves are very rarely dangerous. Really it's about keeping calm and doing what we are trained to do: the basics, like airway management. All dental practices now have buccal midazolam in their drugs kits so use that. If the seizure 
goes on for more than five minutes call the ambulance. So it's quite simple really.

The other thing that is important when you treat patients with epilepsy is to make sure they have taken their anti-epileptic drugs. The most common trigger for a seizure is when people either don't take them or when they have a gastrointestinal upset and the drugs are not working properly.

Also manage the patient's anxiety because anxiety is a well-known trigger for seizures. All the things that we do to calm our patients and build a rapport with them are very important. You can use sedation to help this, for example, oral benzodiazapines, inhalation or IV sedation.

Seizures are the most commonly reported medical emergency in general dental practice. However, I suspect someone in general dental practice might only come across a seizure once every seven years. The problem is if someone goes unconscious on you and they are unresponsive, you need to work out whether it's a faint or more than that. In the last ten years there has been a lot done in the profession about improving medical emergencies training so I think people are a lot more skilled than they once were.

If you were Minister for Health, what would you do to improve secondary care for special needs patients in the UK?

For me, the work that is being done now on establishing care pathways in the specialties is absolutely vital. There are care pathways being developed in all the specialties on a national basis. If I was Minster I would want to speed that work up. The document Commissioning excellence in dental services proposing care pathway implementation was out last year but progress has been rather patchy and slow. The impetus tends to dwindle unless it is driven and this needs more momentum injected into it because I think that it is essential. If it doesn't get seen through there is a huge lost opportunity. The financial pressures at a local level are very intense at the moment and local commissioners inevitably are looking for ways to make cost savings. Without the proposed care pathways in place it's quite a difficult negotiation to have with them. The care pathways should establish a clear remit for each speciality, including special care dentistry.

The government also are planning to introduce a tariff for secondary care, including special care procedures. I think that tariff is extremely important because otherwise the financial pressures tend to rule the day. The NHS has a duty of care to look after the most vulnerable in our society - that's why it was set up.

\section{What is the most important thing for a general dental practitioner to remember when dealing with a physically disabled patient?}

It is really about respecting their wish to be independent, like anyone else. Once people become physically disabled their independence becomes all the more precious to them. As well as the obvious things like adapting the surgery and having physical access, it's more about respecting their wish to be independent. So, for example, asking them if they want any help to transfer to a dental chair before just assuming that they need help. They will tell you if they do.

\section{What makes you get out of bed in the morning?}

I think it's just the sense that there is a job to do so let's get on with it. I don't have any other glamorous answer to that. There is an important job to do and I get itchy unless I am able to get on with it.

\section{Is it possible to successfully treat those with dementia using preventive dentistry?}

The short answer is no. In the early stages of dementia it is possible to use diet advice which we give to carers, families and the patients themselves. The reality is that as their condition progresses, their quality of life and their ability to do everyday things dwindles to such an extent that oral care goes out of the window really. In special care dental services we are asked to see people at the end of their progression of dementia, when they are starting to lose their appetite and are losing weight. Their families are then just concerned about their weight loss and whether or not they are in pain. So we tend to end up just treating them for obvious causes of oral pain that you can see and diagnose. It's more palliative dental care rather than active intervention. We do try but you have to accept the reality of living with a condition like dementia which makes day-to-day life difficult.

\section{When treating very anxious patients, what do you find is the most effective way to calm them?} It sounds so basic and obvious but you can go a long way by taking just a few moments to listen to them and to acknowledge the fact that they are anxious and stressed. It is important to find out what makes them most anxious about coming to you and really just showing them that you are on their side; that you want to help them. It depends what they want too. A lot of anxious patients will want to just come and get the treatment done in the easiest way possible, via inhalation or IV sedation if they are extremely anxious. There are others that want to beat their phobia and come to the dentist like anybody else. Some of those respond well to desensitisation and cognitive behavioural therapy.
I used to treat a lot of phobic patients and it is really quite surprising how it jumps across unconsciously from them to you. I ended up feeling deskilled and nervous about the job myself. You start to believe their take on it; that actually having an ID block or something is a terrifying event. One of the most helpful things for me is having dentistry done on myself because you realise that, although it's not very pleasant, it's not terrifying, certainly not as terrifying as they would have you believe!

\section{What questions would you ask a dental student showing an interest in specialising in special care dentistry?}

I would be curious as to why. What aspects of their course have they found most interesting? They should look back on days that they came away from work feeling that they really enjoyed it so they can try and pin down the aspects that made it fulfilling for them. It's important to encourage them to hone in on what most gives them a buzz. Really we are all different but if you hone your working life to the things that you are interested in then that is going to keep you sustained throughout a 40 year career.

We have quite a few enquires about specialising in special care dentistry from students and particularly those in development trainee posts. Special care, now that it's a recognised speciality with proper training posts and postgrad examinations, is an attractive and viable option as a career. I wish it had been there 30 years ago when I started out. It would have been an obvious choice for me.

\section{INTERVIEW BY RUTH DOHERTY}

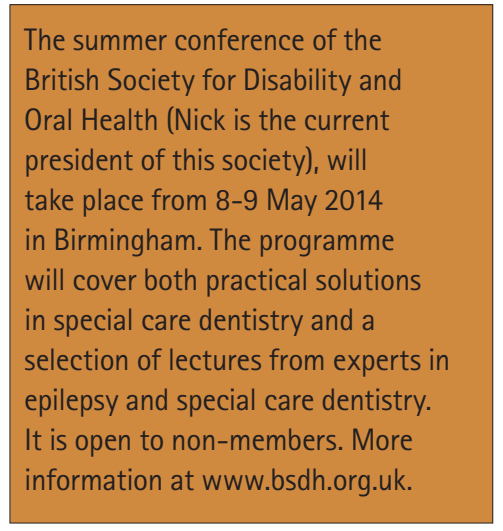

